\title{
Fiber Takviyeli Yapıştırıcıların Kullanıldığı Tek Tesirli Yapışma Bağlantılarında Hasar Analizi
}

\section{Failure Analysis of Fiber Reinforced Adhesively Single Lap Joints}

\section{Kadir TURAN ${ }^{1 *}$, Sinan Barut ${ }^{2}$}

${ }^{1}$ DicleÜniversitesi, Makina Mühendisliği Bölümü, Diyarbakır, kturan@dicle.edu.tr

${ }^{1}$ DicleÜniversitesi, Makina Mühendisliği Bölümü, Diyarbakır, sinanbarut.1@ gmail.com

\begin{tabular}{|c|c|}
\hline MAKALE BİLGİLERİ & ÖZ \\
\hline Makale geçmişi: & \multirow{5}{*}{$\begin{array}{l}\text { Bu çalışmada; tek yön cam fiberlerle takviye edilmiş yapıştırıcılar kullanılarak üretilmiş tek tesirli yapışma } \\
\text { bağlantılarının hasar davranışları deneysel yöntemlerle araştırılmıştır. Kompozit levhaların tek tesirli bağlantılar } \\
\text { ile birleştirilmesinde epoksi yapıştırıcı emdirilmiş fiberler kullanılmıştır. İki kompozit levha arasına yapıştırıcı } \\
\text { emdirilmiş fiber tabakaları kullanılarak bağlantının güçlendirilmesi amaçlanmıştır. Takviye edilmiş yapış̧ırıcılar } \\
\text { ile elde edilen bağlantıların hasar yükleri, takviye edilmemiş yapıştırıcı ile birleştirilmiş bağlantıların hasar } \\
\text { yükleri ile karşılaştırılmış̧ır. Ayrıca fiber takviye açısının etkisini araştırmak için } 0^{\circ}, 15^{\circ} 30^{\circ} \text { ve } 45^{\circ} \text { fiber takviye } \\
\text { açıları kullanılmıştır. Deneysel çalışma sonucunda yapıştırıcıların takviye edilmesinin hasar yüklerini } \% 7^{\circ} \text { ye } \\
\text { varan oranlarda arttırabildiği belirlenmiştir. }\end{array}$} \\
\hline Geliş: 4 Ocak 2021 & \\
\hline Düzeltme: 2 Şubat 2021 & \\
\hline Kabul: 11 Şubat 2021 & \\
\hline Anahtar kelimeler: & \\
\hline
\end{tabular}

Doi: $10.24012 /$ dumf. 853260

\begin{tabular}{|c|c|}
\hline ARTICLE INFO & ABSTRACT \\
\hline Articlehistory: & \multirow{5}{*}{$\begin{array}{l}\text { In this study; experimental failure analysis was investigated on adhesively single-lap joints produced using } \\
\text { adhesives reinforced with uni-directional glass fibers. Epoxy adhesive impregnated fiber were used to join } \\
\text { composite plates with single-lap joints. It is aimed to strengthen the joint by using fiber layers impregnated with } \\
\text { adhesive between the two composite plates. The failure loads of the joints obtained with reinforced adhesives } \\
\text { were compared with the failure loads of the joints attached to the non-reinforced adhesive. Also, } 0^{\circ}, 15^{\circ} 30^{\circ} \text { and } \\
45^{\circ} \text { fiber reinforcement angles were used to investigate the effect of fiber reinforcement angle. As a result of the } \\
\text { experimental study, it was determined that reinforcing the adhesives can increase the damage loads by up to } 7 \% \text {. }\end{array}$} \\
\hline Received: 4 January 2021 & \\
\hline Revised: 2 February 2021 & \\
\hline Accepted: 11 February 2021 & \\
\hline$K$ & \\
\hline
\end{tabular}

Single -Lap Joints, composite plates, reinforcing of adhesive

* Sorumlu yazar / Correspondence

Kadir TURAN

$\checkmark$ kturan@dicle.edu.tr 


\section{Giriș}

Kompozit malzemelerin birleştirilmesinde yapışma bağlantıları oldukça yaygın bir uygulamadır. Yapışma bağlantısı; birbirine birleştirilecek iki yüzey arasına uygulanan yapıştırıcı ile elde edilir. $\mathrm{Bu}$ birleştirmenin geometrik yapısı bağlantının türünü belirler. Gerilme yığılmalarını azaltması ve birleştirilen parçalara zarar vermemesi bu bağlantı türünün en önemli avantajıdır. En büyük dezavantajlarından biri ise yapışma için belirli bir yüzey alanına duyulan ihtiyaçtır. Bindirme mesafesi olarak ta adlandırılan iki parçanın üst üste geldiği bu durum bağlantı mukavemetini etkilemektedir. Bağlantı mukavemetinin istenen seviyeye getirilmesi bindirme mesafesi, yapıştırıcı kalınlığı ve yapışan kalınlığı gibi geometrik parametrelere bağlıdır. Yapışma olayı hem kimyasal hemde fiziksel bağlar içerdiğinden geometrik parametrelerin yanı sıra kimyasal uyum ve yapıştırıcı mukavemeti de bağlantı mukavemeti üzerine belirleyici rol oynar. Bağlantı mukavemetinin arttırılması için yapıştırıcının mukavemetini etkileyebilecek araştırmaların yapılması önemlidir.

Giv vd. (2018) yaptıkları derleme çalışmada mikro ve makro parçacıklarla takviye edilmiş yapıştırıcıların kullanıldığı bağlantıların mukavemeti üzerine kullanılan takviyelerin etkilerini tartışmışlardır [1]. Jojibabu vd. (2016) yaptıkları çalışmada farklı nano-karbon dolgular kullanılarak takviye edilmiş yapıştırıcıların kullanıldığı tek tesirli yapışma bağlantılarının mukavemetini, termal kararlılık ve reholojik özelliklerinin değişimlerini deneysel yöntemlerle araştırmışlardır. Bağlantı mukavemetinin ağırlıkça \%1 oranında kullanılması ile bağlantı mukavemetinin saf yapıştırıcı kullanılan bağlantıya göre \% 53'e varan oranlarda arttığını belirlemişlerdir[2]. Udatha vd. (2020) doğal fiberler ile güçlendirilmiş yapıştırıcılar kullanılarak birleştirilmiş 6061 alüminyum levhaların tek tesirli yapışma bağlantılarının mukavemeti üzerine etkilerini sayısal yöntemlerle araştırmışlardır. Sonuç olarak bağlantının kayma gerilmelerinin saf epoksi yapıştırıcıya göre içerisine eklenen takviyeler ile arttığını belirlemişlerdir [3].Hülagü vd. (2020) çift tesirli yapışma bağlantıları ile birleştirilmiş 2024 alüminyum levhaların bağlantı mukavemeti üzerine nano karbon dolguların etkilerini deneysel yöntemlerle araştırmışlardır. Bağlantı mukavemetinin nano karbon dolgular ile \%81'e varan oranlarda arttığını belirlemişlerdir [4]. Khalili vd. (2008) tek tesirli yapışma bağlantıları ile birleştirilmiş cam fiber/epoksi kompozit levhalarda çekme, eğilme, darbe ve yorulma mukavemeti üzerine tek yönlü ve kırpılmış cam fiber takviyeli yapıştırıcıların etkilerini araştırmışlardır. En yüksek bağlantı mukavemeti değerlerinin hacimce $\% 30$ yoğunluktaki takviye için elde edildiğini belirlemişlerdir. Bağlantı mukavemeti üzerine takviye etkisi olarak; çekme mukavemetinin $\% 72$, eğilme mukavemetinin \% 112 ve çarpma mukavemetinin \%63 oranlarında arttığını tespit etmişlerdir [5]. Turan (2016) tarafindan yapılan çalışmada tek ve çift bindirmeli yapışma bağlantılarının mukavemeti üzerine fiber takviye açısının etkisini araştırmıştır. Örgülü cam fiber/epoksi kompozit levhaların birleştirilmesinde kullanılan yamaların fiber takviye açısının bağlantı mukavemeti üzerine etkileri incelenmiştir. Yama fiber takviye açısı olarak $0^{\circ}, 15^{\circ}, 30^{\circ}$ ve $45^{\circ}$ kullanılması ile bağlantı mukavemetinin \% 10 ile $\% 45$ arası değişen oranlarda arttığını belirlemiştir [6]. Ayatollahi vd. (2017) karbon nanotüp ve silika katkılı yapıştırıcılarla birleştirilmiş tek tesirli yapışma bağlantısı ile birleştirilmiş alüminyum levhalarda kesme mukavemeti ve kopma uzamasının değişimlerini araştırmışlardır. Yapıştırıcıların güçlendirilmesi sonucunda kesme mukavemetinin \%27.2'ye kadar, kopma uzamasının ise \%19.7 değerine kadar artabildiğini tespit etmişlerdir [7]. Khalili vd.(2010) nano kil katkılı epoksi yapıştırıcı ile tek tesirli yapışma bağlantısı ile birleştirilmiş kompozit levhalarda kesme ve darbe mukavemetinin değişimini araştırmışlardır. Nano kil katkının bağlantının kesme mukavemetini \% 28, enerji yutma kapasitesini ise \% 22'ye varan değerlerde arttırdığını belirlemişlerdir [8]. Meguid ve Sun (2003) tarafindan yapılan çalışmada 6064 alüminyum levha ve karbon/epoksi kompozit levhanın tek tesirli yapışma bağlantıları ile birleştirmesinde takviye edilmiş yapıştırıcıların bağlantı mukavemeti üzerine etkilerini araştırmışlardır. 
Yapıştırıcının takviye edilmesinde karbon nano tüpler ve alüminyum nano tüpler kullanılmıştır. Takviye edilmiş yapıştırıcılarla yapılan tek tesirli yapışma bağlantısının mukavemetinin $\% 12.5$ ile $\% 50$ aras1 değișen oranlarda arttırdı ğını belirlemişlerdir [9]. Turan ve Pekbey (2014) atık kompozit tozları ile takviye edilmiş yapıştırıcılarla birleştirilen cam fiber/epoksi kompozit levhaların tek tesirli yapışma bağlantı mukavemetinin değişimini araştırmışlardır. Atık karbon fiber/epoksi ve cam fiber/epoksi kompozitlerin tozları ile takviye edilmiş yapıştırıcılardan elde edilen bağlantı mukavemetinin \% 1.3 ile $\% 22.8$ arası değişen oranlarda arttırdığını tespit etmişlerdir [10]. Silva vd. (2012) mikro mantar katılarak takviye edilen yapıştırıcılar ile üretilmiş tek tesirli yapışma bağlantısının kırılma davranışlarını araştırmışlardır. Takviye miktarının artmasına bağlı olarak hasar tiplerinin değiştiğini belirlemişlerdir [11].

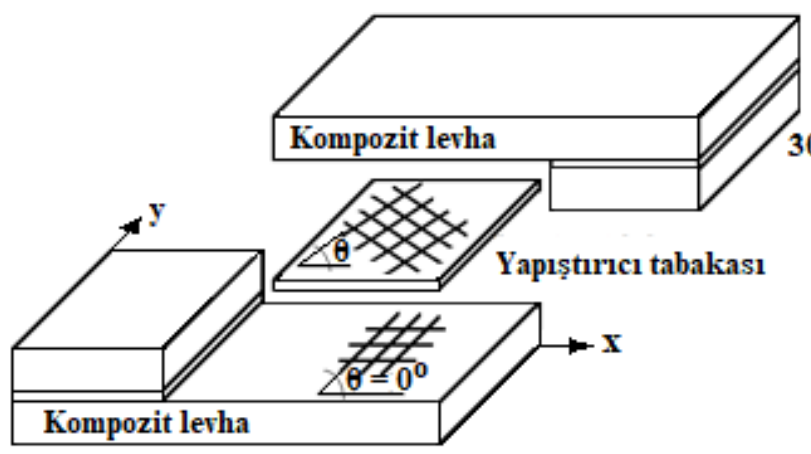

Şekil 1. Problemin tanımı.

Şekil 1'de gösterilen bağlantıda yapıştırıcı kalınlığ1 olarak0.3 mm, bindirme uzunluğu olarak ta $30 \mathrm{~mm}$ değeri kullanılmıştır. Yapıştırıcı kalınlığı ve bindirme uzunluğunun ayarlanabilmesi ve tüm numunelerde standart hale getirilebilmesi için Şekil 2'de gösterilen kalıplar kullanılmıştır. Üç boyutlu yazıcıdan üretilen kalıplarda her bir bağlantı türü için üçer adet numune üretilmiştir.

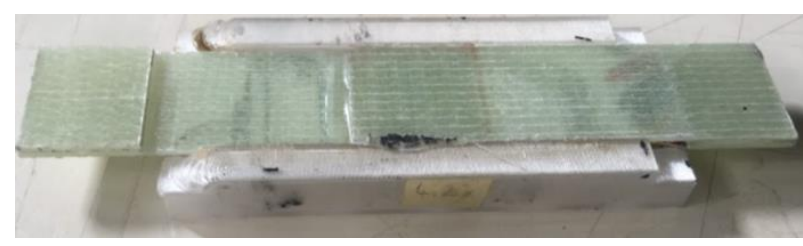

Şekil 2. Yapışma bağlantısının üretildiği kalıp.
$\mathrm{Bu}$ çalışmada, tek yönlü fiber kumaşı ile güçlendirilmiş yapıştırıcılar kullanılarak üretilmiş tek tesirli yapışma bağlantılarının hasar davranıșları araștırılmıștır. Fiber takviye açısının etkilerini inceleyebilmek için $0^{\circ}, 15^{\circ}, 30^{\circ}$ ve $45^{\circ}$ açıları kullanılmıştır. Takviyeli yapıştırıcı ile elde edilen bağlantıların mukavemeti sadece yapıştırıcının kullanıldığ ile karşılaştırılmıştır. Elde edilen sonuçlar tablo ve grafikler halinde sunulmuştur.

\section{Deneysel Çalışma}

Tek tesirli yapışma bağlantılarını üretmek için örgülü cam fiber/epoksi kompozit levhalar, tek yön cam fiberler ve Loctite 9466 epoksi yapıştırıcı kullanılmıştır. Deneylerde kullanılan kompozit levhalar $350 \mathrm{gr} / \mathrm{m}^{2}$ ve yapıştırıcıyı güçlendirmek içinse $250 \mathrm{gr} / \mathrm{m}^{2}$ yoğunluğa sahip tek yön cam fiberler kullanılmıştır. Şekil 1'de problemin boyutları ve tek tesirli yapışma bağlantısının şekli gösterilmiştir.

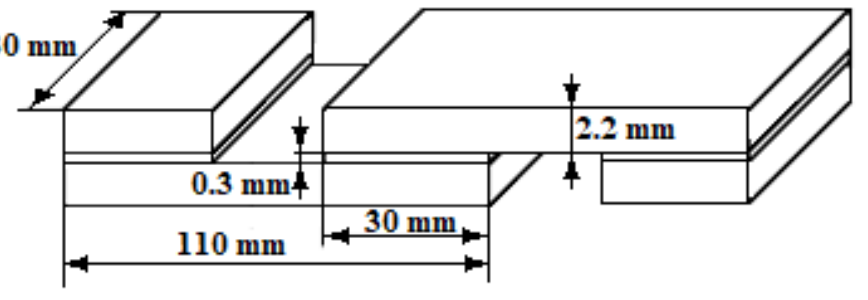

Yapışma bağlantılarının hazırlanırken İzoreel firmasından temin edilen örgülü cam fiber/epoksi kompozit levhalar $110 \mathrm{~mm} \times 30 \mathrm{~mm} \times 2.2 \mathrm{~mm}$ boyutlarında kesilerek bağlantıya hazır hale getirilmiştir. Kompozit levhaların yapıștırılacak yüzeyleri $30 \mathrm{~mm}$ uzunluğunda 600grid kum zimpara ile düzleştirilmiştir. Pamuklu bez ve aseton kullanılarak silinen yüzeyler kuruması için bekletilmiştir. Yapıştırıcıyı takviye etmek amacı ile kullanılacak tek yön cam fiberlere Loctite 9466 epoksi yapıştırıcı emdirilerek 30mmx30mm boyutlarında kesilmiş ve yapışma bölgesine yerleştirilmiştir. Oda sıcaklığında bir hafta süre ile kürleşmesi beklenmiştir. Kürleşme süresi sonunda statik çekme deneyi ile yapışma bağlantıları kırılana kadar yüklenmiştir. Statik 
çekme deneyleri $100 \mathrm{kN}$ kapasiteli İnstron BS8800 üniversal çekme test makinesinde 1 $\mathrm{mm} / \mathrm{dk}$ çekme hızında ve oda sıcaklığı şartlarında gerçekleştirilmiştir. Şekil 3'te deney düzeneği görülmektedir.

Statik çekme deneylerinden elde edilen yük/uzama sonuçları kullanılarak bağlantının hasar davranışlarının görülebileceği grafikler elde edilmiştir. Deneylerde üst çene sabit olmak üzere alt çeneden statik çekme yükü uygulanmıştır. Deneyler sırasında tek tesirli yapışma bağlantılarının eksantrik yapısının sonuçları etkilememesi için bağlantıların serbest uçlarının ters kısımlarına pabuçlar yapıştırılmıştır. $\mathrm{Bu}$ bağlantı pabuçları bağlantı için kullanilan kompozit levhalardan
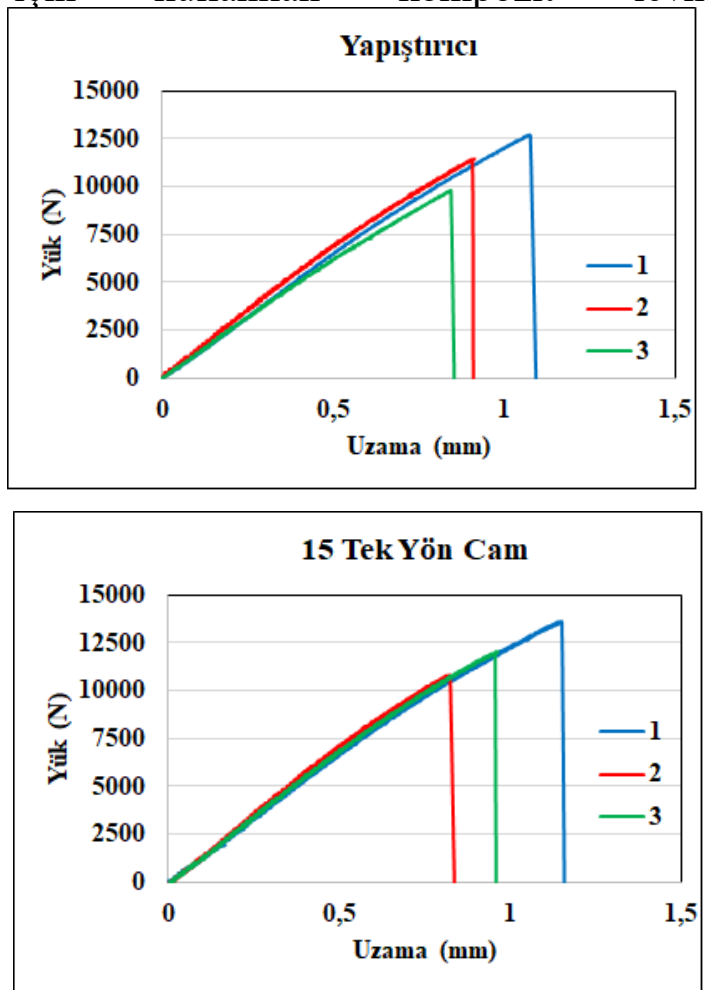

30mx30mm boyutlarında imal edilmiştir.

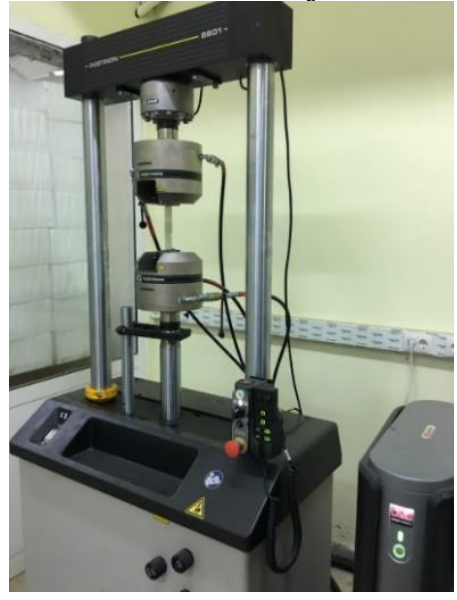

Şekil 3. Deney düzeneği.
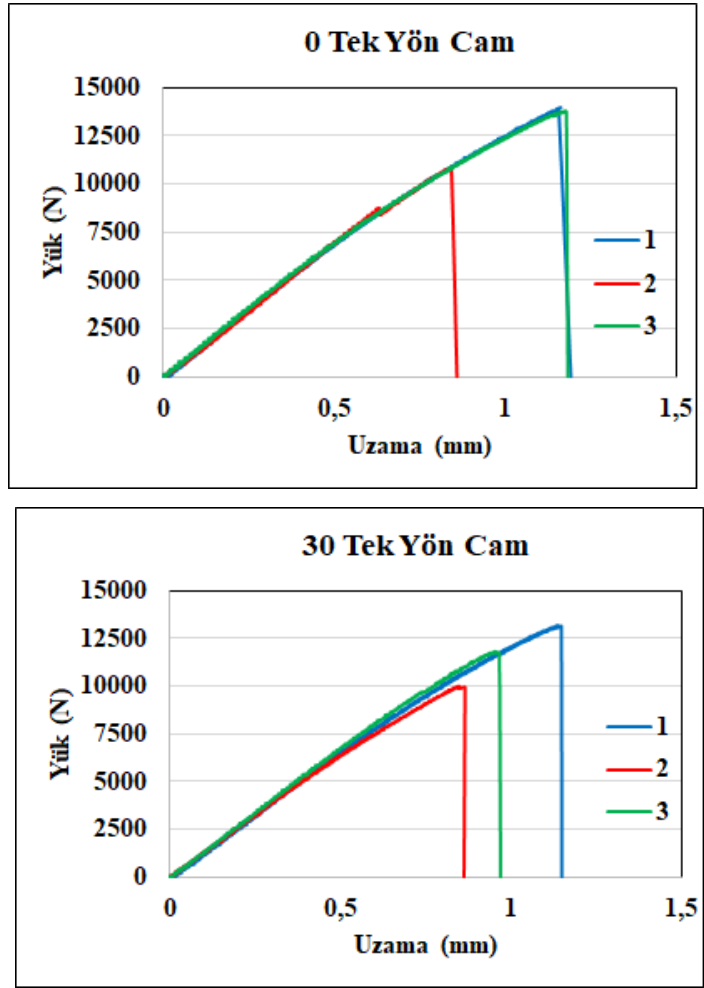

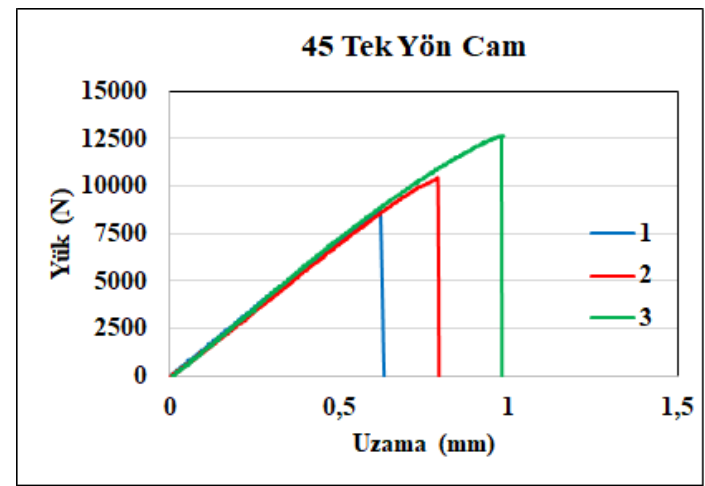

Şekil 4. Deneysel çalışma sonuç grafikleri. 
Şekil 4'te deneysel çalışma sonucunda katkısız yapıştırıcı ve $0^{\circ}, 15^{\circ}, 30^{\circ}$ ve $45^{\circ}$ fiber takviye açılı fiberler kullanılarak takviye edilmiş yapıștırıcıların yük/uzama sonuç grafikleri gösterilmiştir.

Şekil 4'ten görüldüğü gibi yük ile uzama değerleri tek tesirli yapışma bağlantılarının genel davranışlarına uygun olarak lineer olarak artmış ve belirli bir yük değerine (en büyük hasar yükü) ulaşıldığında aniden düşmüştür. Grafiklerde 1, 2 ve 3 olarak deney numunelerinin numaraları gösterilmiştir. Görülen bu davranış tek tesirli yapışma bağlantılarının hasar yüklerinin araştırıldığı [1-10] numaralı referans çalışmalarda da gözlemlenmiş̧tir.

\section{Sonuçlar}

Şekil 4'te sunulmuş olan deneysel çalışma sonuç grafiklerindeki her bir numuneye ait en büyük yük değerlerinin aritmetik ortalamaları alınarak hasar yükü değerlerine ulaşılmıştır. Bu sonuçlar kullanılarak Şekil 5 'te yer alan grafik çizilmiştir.

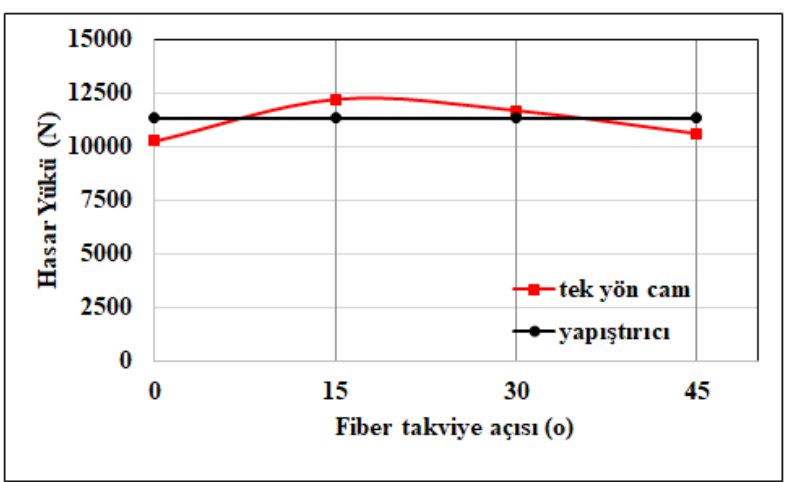

Şekil 5. Hasar yüklerinin karşılaştırılması.

Şekil 5'ten görüldüğü gibi yapıştırıcının tek yön cam fiber kullanılarak takviye edilmesi

\begin{tabular}{|c|c|c|c|c|}
\hline $\begin{array}{l}\text { Takviyesiz } \\
\text { Yapıştırıcı }\end{array}$ & $\begin{array}{l}0^{\circ} \text { Cam fiber Takviyeli } \\
\text { Yapıştırıcı }\end{array}$ & $\begin{array}{l}15^{\circ} \text { Cam fiber } \\
\text { Takviyeli Yapıştırıcı }\end{array}$ & $\begin{array}{l}30^{\circ} \text { Cam fiber } \\
\text { Takviyeli Yapıştırıcı }\end{array}$ & $\begin{array}{l}45^{\circ} \mathrm{Cam} \text { fiber } \\
\text { Takviyeli Yapıştırıcı }\end{array}$ \\
\hline $\begin{array}{l}\text { Kohezyon } \\
\text { Hasar1 }\end{array}$ & & $\begin{array}{l}\text { Adhezyon } \\
\text { Hasarı }\end{array}$ & $\begin{array}{l}\text { Kohezyon } \\
\text { Hasarı }\end{array}$ & $\begin{array}{l}\text { Adhezyon } \\
\text { Hasarı }\end{array}$ \\
\hline $\begin{array}{l}\text { Adhezyon } \\
\text { Hasar1 }\end{array}$ & $\begin{array}{l}\text { Adhezyon } \\
\text { Hasarı }\end{array}$ & $\begin{array}{l}\text { Kohezyon } \\
\text { Hasarı }\end{array}$ & $\begin{array}{l}\text { Adhezyon } \\
\text { Hasarı }\end{array}$ & \\
\hline $\begin{array}{l}\text { Adhezyon } \\
\text { kohezyon hasarı }\end{array}$ & Adhezyon hasarı & $\begin{array}{l}\text { Adhezyon + kohezyon } \\
\text { hasar1 }\end{array}$ & $\begin{array}{l}\text { Adhezyon + kohezyon } \\
\text { hasar1 }\end{array}$ & Adhezyon hasarı \\
\hline
\end{tabular}

Şekil6. Deneysel çalışma sonucunda gözlemlenen numunelerde meydana gelen hasar tipleri. sonucunda hasar yüklerinin değiştiği görülmektedir. Hasar yüklerinin takviye açısından değerlendirmesinde $0^{\circ}$ ve $45^{\circ}$ fiber takviye açısı değerleri için yapıșma bağlantısı mukavemetinin sadece yapıștırıcı kullanılmış numunelere göre düşük olduğu, $15^{\circ}$ ve $30^{\circ}$ fiber takviye açıları içinse hasar yüklerinin artış gösterdiği belirlenmiştir. En yüksek hasar yükünün $15^{\circ}$ fiber takviye açılı yapıştırıcı için 12163.06 N olarak elde edilirken, en düşük hasar yükü ise $0^{\circ}$ fiber takviye açısına sahip yapıştırıcı için $10261.51 \mathrm{~N}$ olarak elde edilmiştir. Deneysel çalışma sonuçlarının daha iyi anlaşılması açısından elde edilen değerler Tablo 1'de sunulmuştur.

Tablo 1. Hasar yüklerinin karşılaştırılması tablosu

\begin{tabular}{|c|c|c|c|}
\hline $\begin{array}{c}\text { Fiber } \\
\text { takviye } \\
\text { açısı }\left(^{\circ}\right)\end{array}$ & $\begin{array}{c}\text { Takviyeli } \\
\text { Yapıştırıcı } \\
\text { Hasar Yükü } \\
(\mathrm{N}) \\
\end{array}$ & $\begin{array}{c}\text { Takviyesiz } \\
\text { Yapıştırıcı } \\
\text { Hasar Yükü } \\
\text { (N) }\end{array}$ & $\begin{array}{c}\text { Değişim } \\
\text { Oranı } \\
\%\end{array}$ \\
\hline 0 & 10261.51 & 11308.9 & -9.25 \\
\hline 15 & 12163.06 & 11308.9 & +7.56 \\
\hline 30 & 11658.5 & 11308.9 & +3.09 \\
\hline 45 & 10608.53 & 11308.9 & -6.19 \\
\hline \multicolumn{2}{|c|}{ + Artış oranı } & \multicolumn{2}{|c|}{ - Azalma oranı } \\
\hline
\end{tabular}

Tablo 1' incelendiğinde; fiber takviye açısının bağlantı mukavemetini $\% 7$ civarında değişen oranlarda arttırabildiği görülmüştür. Yapışma bağlantılarının hasar yükleri değişiminin önemli olduğu kadar hasar tiplerinin değişimi de önem arz etmektedir. Şekil 6'da deneysel çalışma sonucunda kırılmış yüzeylerin fotoğrafları sunulmuştur. 
Şekil 6'dan görüldüğü gibi sadece yapıştırıcı, $15^{\circ}$ ve $30^{\circ}$ fiberler ile takviye edilmiş yapıştırıcılar kullanılarak üretilen bağlantılarda adhezyon ve kohezyon hasarının birlikte gerçekleştiği görülmektedir. $\mathrm{Bu}$ durum hasar yüklerinin artışına sebep olmaktadır. Fiber takviye açısı olarak $0^{\circ}$ ve $45^{\circ}$ fiber takviye açılarının kullanıldığı bağlantılarda ise sadece adhezyon hasarı meydana gelmiştir. Bu takviye açılarının hasar yüklerinin düşük olma sebebi de sadece adhezyon hasarı meydana gelmiş olmasidir.

\section{Tartışma.}

$\mathrm{Bu}$ çalışmanın ana amacı sürekli fiberler kullanılarak takviye edilmiş yapıştırıcıların tek tesirli yapışma bağlantısı ile birleştirilmiş kompozit levhalarda hasar davranışlarının araştırılmasıdır. Yapışma bağlantılarında genellikle yapışan mukavemeti yapıştırıcı mukavemetinden büyük olduğu için bağlantının mukavemeti yapışma mukavemetine bağlı olmaktadır. Yapışma mukavemetinin arttırılabilmesi ancak adhezyon ve kohezyon kuvvetlerinin dengeli bir kullanımı ve bağlantı türü ile ilgili olmaktadır. Yapıştırıcıların takviye edilmesinde ana amaç aynı yapıştırıcı kullanılarak daha mukavemetli bağlantılar elde edilebilmesidir. $\mathrm{Bu}$ amaçla yapılan araştırmada sürekli fiberler ile takviye edilmiş yapıştırıcıların bağlantı mukavemetini özellikle fiber takviye açısına bağlı olarak değiştirdiği görülmüştür. Sonuç olarak $15^{\circ}$ ve $30^{\circ}$ fiber takviye açıll tek yön cam fiber kumaşlar kullanılarak yapılan güçlendirmenin başarılı olduğu belirlenmiştir. $\mathrm{Bu}$ çalışmadan elde edilen değişimlerin göz önüne alınarak farklı fiber takviye çeşitlerinin kullanılması bağlantı mukavemeti açısından yapılacak farklı çalışmalara 1şık tutacaktır.

\section{Teşekkür}

Bu çalışmayı MÜHENDİSLİK 18.014 numaralı proje ile desteklediği için DÜBAP birimine teşekkür ederiz.

\section{Kaynaklar}

[1] Giv A.N., Ayatollahi M.R., Ghaffari S.H., Silva L.F.M., (2018). Effect of reinforcements at different scales on mechanical properties of epoxy adhesives andadhesive joints: a review, Journal of Adhesion,94, 13, 1082-1121.

[2] Jojibabu P., Jagannatham M., Haridoss P., Ram G.D. J., Deshpande A.P.,Bakshi S.R., (2016). Effect of different carbon nano-fillers on rheological properties and lapshear strength of epoxy adhesive joints, Composites Part: A, 82, 53-64.

[3] Udatha P., Babu Y.N., Satyadev M., Bhagavathi L.R., (2020). Effect of natural fibers reinforcement on lap-shear strength of adhesive bonded joints,Materials Today: Proceedings,23, 541-544.

[4] Hülagü B., Acar V., Aydın M.R., Aydın O.A.,Gök S., Ünal H.Y., Pekbey Y., Akbulut H., (2020). Experimental modal analysis of graphene nanoparticle reinforced adhesively bonded double strap joints, Journal of Adhesion, https://doi.org/10.1080/00218464.2020.1734793.

[5] Khalili S.M.R., Shokuhfar A., Hoseini S.D., Bidkhori M., Khalili S., Mittal. R.K., (2008). Experimental study of the influence of adhesive reinforcement in lap joints for composite structures subjected to mechanical loads, International Journal of Adhesion \& Adhesives, 28, 436- 444.

[6] Turan K., (2016). Kompozit malzemelerde yapışma bağlantılarının mukavemeti üzerine yama fiber takviye açısı etkisi, Dicle Üniversitesi Mühendislik Fakültesi Mühendislik Dergisi,7, 1, 129-136.

[7] Ayatollahi M. R., Giv A. N., Razavi S. M. J., Khoramishad H., (2017). Mechanical properties of adhesively single lap bonded joints reinforced with multi walled carbon nanotubes and silica nanoparticles, Journal of Adhesion,93, 11, 816-913.

[8] Khalili S.M.R., Tavakolian M., Sarabi A., (2010). Mechanical Properties of Nanoclay Reinforced Epoxy Adhesive Bonded Joints Made with Composite Materials, Journal of Adhesion Science and Technology, 24, 1917-1928.

[9] Meguid S.A., Sun Y., (2004). On the tensile and shear strength of nano-reinforcedcomposite interfaces, Materials and Design,25, 289-296.

[10] Turan K., Pekbey Y., (2015). Progressive Failure Analysis of Reinforced-Adhesively Single-Lap Joint, Journal of Adhesion, 91, 962-977.

[11] Silva C.I., Barbosa, A.Q., Carbas R.J.C., Marques E.A.S., Safar A.A., Da Silva L.F.M., (2012). Influence of cork microparticles on the fracture type in single lap joints, Journal of Adhesion, 88, 452470 . 